\title{
Earned value method as a tool for project control
}

\author{
Agata Czarnigowska \\ Institute of Construction, Faculty of Civil and Sanitary Engineering, \\ Lublin University of Technology, 20-618 Lublin, Nadbystrzycka 40, \\ e-mail: a.czarnigowska@pollub.pl
}

\begin{abstract}
Earned Value is a well-known project management tool that uses information on cost, schedule and work performance to establish the current status of the project. By means of a few simple rates, it allows the manager to extrapolate current trends to predict their likely final effect. The method is based on a simplified model of a project, but proved to be useful in practice of cost control. It is being developed to account better for schedule and time aspects. The paper outlines the basic principles of the method and its recent extension, the Earned Schedule method, and, with help of a few examples, investigates into assumptions that affect their diagnostic and predictive accuracy.
\end{abstract}

Key words: Earned Value, project control.

\section{Purpose of earned value}

The Earned Value method has been developed as a tool facilitating project progress control. It is used for determining a project's status (is it behind or ahead of schedule? is it over or under budget?) and the scale of current variances from the plan. Moreover, it allows a project manager to make inferences on the final effect of the project in terms of cost and, to some extent, in terms of duration, by extrapolating current trends [1,2].

The method is simple: it assumes a simplified model of a project, and calculations require nothing more than four basic arithmetic operations. However, the method has been recognized as a useful tool by many practitioners and government agencies and has become a standard in project management. It proved to be versatile enough to be applied to any type of a project, ranging from defence schemes worth millions and extending on many years to minor IT projects. The analysis can be conducted on any level of work breakdown structure and used by both clients and contractors.

The method, if to be used efficiently, requires a disciplined approach to collection of data on project cost and progress (on weekly basis) and the findings are to be processed immediately. The purpose is to detect any deviation as soon as possible, so that there is enough time to asses if the deviation is dangerous for the project and, if necessary, to take corrective actions. 


\section{The idea of earned value analysis and interpretation of its results}

\subsection{Input data}

Figure 1 presents the idea of the Earned Value project control. The analysis requires following inputs $[1,2]$ :

- BCWS - Budgeted Cost of Works Scheduled - the baseline for the analysis, cumulated planned costs related to time of their incurrence;

- BCWP - Budgeted Cost of Work Performed - a measure of physical progress of works expressed by cumulated planned cost of works actually done related to time, it is also called Earned Value (like the method it is used by);

- ACWP - Actual Cost of Work Performed - cumulated ammount payable for works done related to time;

- BAC - Budget at Completion - total planned cost of the whole project, it equals $B C W S$ at the planned finish;

$-T$ - planned duration of the project.

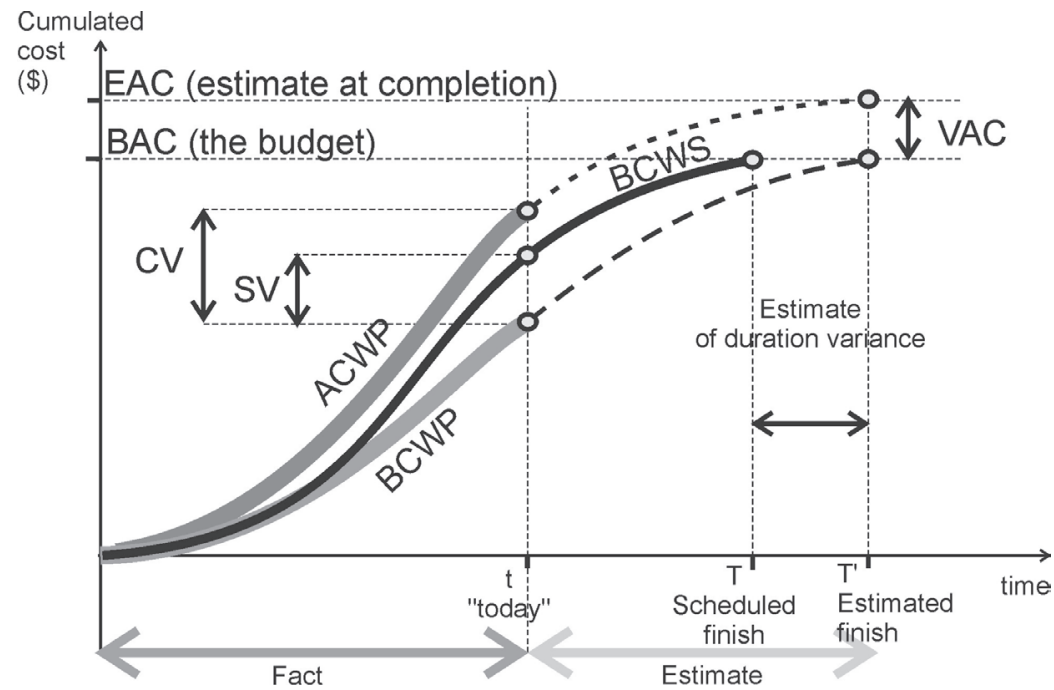

Fig. 1. Earned Value curves; this project is currently ("today") over budget and behind schedule.

\subsection{Project status indicators}

$P C$ - Percentage Complete:

$$
P C=\frac{B C W P}{B A C},
$$

$\mathrm{CV}$ - Cost Variance - a measure of deviation between planned and actual cost of works done until the date of recording progress in money units. If negative, it indicates that the project is over budget:

$$
C V=A C W P-B C W P \text {. }
$$


To capture the scale of deviation, it is often expressed as a fraction of the budgeted cost of works performed:

$$
C V \%=\frac{C V}{B C W P} \cdot 100 \%,
$$

$S V$ - Schedule Variance - a measure of deviation between the actual progress and the planned progress. Though it is interpreted as time deviation, it is expressed in money units. In other words, it is the difference between the planned cost of works that have been done and planned cost of works that should have been done by the reporting date. If negative, it indicates a delay:

$$
S V=B C W P-B C W S \text {. }
$$

To address any distortion caused by the relative value of activities, it is expressed as a fraction of BCWS:

$$
S V \%=\frac{S V}{B C W S}
$$

CPI - Cost Performance Index - compares the planned and actual value of works done, if less than 1 , it indicates that the project has consumed more money than planned, if greater than 1 , there have been savings.

$$
C P I=\frac{B C W P}{A C W P},
$$

SPI - Schedule Performance Index - compares the planned cost of works done with planned cost of works planned; if less than 1, it indicates a delay:

$$
S P I=\frac{B C W P}{B C W S} .
$$

\subsection{Earned Value "forecasting" parameters}

EAC - Estimate at Completion - is calculated at the date of reporting progress to serve as an estimate of the effect of deviations cumulated from the project's start on the total project cost, so it informs how much the project is going to be in the end, if the cost performance index CPI stays the same:

$$
E A C=\frac{B A C}{C P I}
$$

It is clear that $E A C$ is a simple linear extrapolation of current tendencies. It does not allow for any future risks or effects of corrective measures, so it is not a proper forecast. Nevertheless, EAC indicates the potential scale of cost problems. As the Earned Value method requires frequent progress checks from the very beginning of a project, an early EAC-based constatation that current tendencies are likely to double the cost are likely to provide a valuable warning signal and trigger rectifying actions when it is still time.

$E A C$ is not necessarily based on the assumption that future costs are going to follow the today's pattern. Other scenarios can be considered but, as the method 
rests upon a simplified model of a project, linear extrapolation is a rule and it proves to be adequate [3]. The general EAC formula allows for a number of simple scenarios:

$$
E A C=A C W P+\frac{B A C-B C W P}{P F},
$$

i.e. $E A C$ is a sum of costs already committed and the reminder of the budget adjusted by a factor $(P F)$ that reflects the relationship between the project's future and its past. This can be project-specific. Scenarios considered most often are as follows:

1. the cost of remaining task is going to be as planned, i.e. future costs are not related to current costs, $P F=1$, so:

$$
E A C=B A C+C V \text {; }
$$

2. the cost of remaining tasks is going to stay in proportion to current $C P I$ as in equation (8); it ignores the real-life time-cost relationship (if a project is to be accelerated, it usually requires more money);

3. the cost of remaining tasks will be related to current tendencies of both schedule and cost performance, so the $P F$ is a Critical Ratio $(C R)$, called also a Schedule Cost Ratio $(S C R)$ :

$S C I=C P I \cdot S P I$.

Another measure used for forecasting (or rather for simple extrapolation) is TCPI (To Complete Performance Index) - a value of cost performance index that is to be maintained from now on if the project is to be completed to budget. In other words, TCPI is a proportion between the remaining work (expressed in terms of budgeted costs) and the money left from the budget:

$$
T C P I=\frac{B A C-B C W P}{B A C-A C W P} .
$$

If it is much higher than 1 and the current CPI, it indicates the scale of effort needed for searching for economies.

\section{Application of earned value - example}

Figure 2. presents a fragment of a construction project's schedule - a number of tasks of the first stages of the project. Table 1. contains input data collected by the end of the seventh week of the schedule and status indicators calculated on their basis. Inputs are marked grey:

- a budget for each tasks and for the whole project (BAC),

- percentage complete $(P C)$ of each task as measured or estimated during inspection (it is represented by black lines over schedule bars and values above them),

- budgeted costs of works scheduled up to the end of week 7 (BCWS) (e.g. according to the schedule, the task "Piling" should have been completed, so its $B C W S=B A C$, but the task "Slab 1" should be about $66 \%$ complete, so its $B C W S=0,66 \cdot B A C)$,

- actual costs of works performed (ACWS). 


\begin{tabular}{|c|c|c|c|c|c|c|c|c|c|c|c|}
\hline Task & $\mathrm{BAC}$ & 1 & 2 & 3 & 4 & 5 & 6 & 7 & 8 & 9 & 10 \\
\hline Factory & 5000 & $100 \%$ & & & & & & & & & \\
\hline Piling & 120 & & $100 \%$ & & & & & & & & \\
\hline Earthworks & 50 & & 700 & \multicolumn{2}{|c|}{$80 \%$} & & & & & & \\
\hline Pile raft and found. & 100 & & & & & \multicolumn{2}{|c|}{$50 \%$} & & & & \\
\hline Substructure walls & 220 & & & & & & $25 \%$ & & & & \\
\hline Slab 1 & 260 & & & & & & & & & & \\
\hline Ground floor walls & 150 & & & & & & & & & & \\
\hline
\end{tabular}

Fig. 2. Schedule to serve as basis for calculations - project "Factory".

Table 1. $\quad$ Earned Value calculations - project "Factory", end of week 7.

\begin{tabular}{lccccccccccc}
\hline Task & $B A C$ & $P C$ & $B C W S$ & $B C W P$ & $A C W P$ & $S V$ & $C V$ & $C P I$ & $S P I$ & $E A C$ & $T C P I$ \\
\hline Factory & 5000 & $8,50 \%$ & 713,33 & 425,00 & 445,00 & $-288,33$ & $-20,00$ & $96 \%$ & $60 \%$ & 5235,29 & $100,44 \%$ \\
\hline Piling & 120 & $100 \%$ & 120 & 120 & 120 & 0,00 & 0,00 & $100 \%$ & $100 \%$ & 120,00 & - \\
Earthworks & 50 & $100 \%$ & 50 & 50 & 60 & 0,00 & $-10,00$ & $83 \%$ & $100 \%$ & 60,00 & - \\
Pile raft and f. & 100 & $80 \%$ & 100 & 80 & 75 & $-20,00$ & 5,00 & $107 \%$ & $80 \%$ & 93,75 & $80,00 \%$ \\
Sub. walls & 220 & $50 \%$ & 220 & 110 & 110 & $-110,00$ & 0,00 & $100 \%$ & $50 \%$ & 220,00 & $100,00 \%$ \\
Slab 1 & 260 & $25 \%$ & 173 & 65 & 80 & $-108,33$ & $-15,00$ & $81 \%$ & $38 \%$ & 320,00 & $108,33 \%$ \\
Ground f. walls & 150 & $0 \%$ & 50 & 0 & 0 & $-50,00$ & 0,00 & - & $0 \%$ & - & $100,00 \%$ \\
\hline$\ldots$ & $\ldots$ & $0 \%$ & 0 & 0 & 0 & 0 & 0 & - & - & - & \\
\hline
\end{tabular}

The progress of the whole project $(P C)$ is calculated according to formula (1):

$$
P C=\frac{B C W P}{B A C}=\frac{425}{5000}=8,50 \% \text {. }
$$

$B C W S, B C W P, A C W P$ and variances $S V$ and $C V$ for the whole project are sums of values of all tasks. The project's CPI and SPI are calculated on the basis of its $B C W S, B C W P$ and ACWP.

SV i SPI indicate that, by the end of week 7, the tasks "Pile raft...", "Sub. walls" and "Slab 1" have not been completed to the planned extent, so they are delayed. Therefore, the whole project is behind schedule in terms of scope of works i.e. less work has been done than it was planned.

CV i CPI indicate that "Earthworks" and "Slab 1" proved more expensive than planned. Some savings on "Pile raft..." compensated this additional cost only in part, so the project as a whole is over budget.

If the project was to be finished on budget, it would have to be continued with an improved cost performance index $(T C P I)$. If the project was to proceed with current CPI, its total costs would be EAC. 


\section{Practical problems with using earned value}

\subsection{Determination of percentage complete $(P C)$}

It is possible to determine the exact progress of a task only if its result is measurable. For instance, a percentage complete of a task "brick walls" can be calculated by dividing the area of walls measured on site and the area that was planned to be built by the date of progress check; it can be assumed that costs are in proportion to quantity. Usually, direct measurements are possible only for tasks (or works) of the lowest (most detailed) levels of work breakdown structure.

The progress more complex tasks (such as "finishings of second floor") or tasks that do not have tangible or measurable results (as "quality inspection" or "client briefing") has to be estimated. The problem is that such estimates can be biased. The literature on the subject prompts a number of solutions [1,4], e.g.:

- an assumption that a task is $0 \%$ complete until it is done, than it becomes $100 \%$ complete (a rather pessimistic and "safe" approach, but it undervalues partially completed tasks);

- applying a fixed percentage at the beginning of the task $(10 \%$ or $20 \%$ or $50 \%$ ) and keeping it until the task ends, then it becomes 100\% complete;

- "eyeball" assessment i.e. subjective judgement - as it is better to make a rough estimate of a progress than to give up progress monitoring at all.

All the above approaches cause no distortion to the overall picture of the project progress only if applied at low level of work breakdown structure (tasks of duration much lower than the total project duration).

\subsection{Accessibility of actual cost data (ACWS) and basis for budget}

Decision on what costs are to be included in Earned Value analysis is crucial for the project control.

Let's assume that the manager wants to use actual expenditures. There is but a certain lag between a task and related expenditure: labour is paid monthly or weekly, terms of payment for materials are various. Another difficulty - how to treat expenditures on tasks that have not started yet? They could not be included in $A C W P$, so additional work would be required to separate them. It would be also difficult to assess actual costs on the basis of invoices - they can be delayed, and they are likely to concern money spent on a whole delivery or service that may be used for a number of tasks. To sum up - it would be counterproductive to process book-keeping data to get ACWS [6].

Another problem is the scope of costs to be analysed. As a budget is based usually on a bid, it contains some costs that are assigned to tasks artificially - by a percentage rate (overheads). It would be advisable to extract them and create separate tasks. The cost model would be thus more precise and costs easier to control. It is also important to remember that the contractor's $B A C, B C W S, B C W P$ and $A C W P$ do not contain profit and contingencies - it is cost that is to be analysed, not revenues. If the budget was mechanically copied from the bid (and contained profit), and ACWP was recorded as cost only, the analysis would lead to false conclusion that there have been savings. 
From the point of a building contractor it would be convenient to use direct cost as incurred (so e.g. material costs as materials have been built-in). In practice, instead of considering full costs or all direct costs, labour cost can be used for creating the budget for progress control purposes. Certainly, it is advisable only in the case of labour-intensive projects where all tasks require using it. Labour costs are directly measurable and the analysis would be simplified. Alternatively, planned man-hours could be used instead labour costs $[1,6]$

For the reasons mentioned above, the Earned Value's "S-curves" are not the same as those used for project cash flow analysis. This certainly does not facilitate combined interpretation of project performance in terms of work progress, receipts and expenditures.

\subsection{Inferences on future schedule development on the basis of $S V$ i SPI}

It is worth remembering that $S V(\$)$ and $S P I(\%)$ are considered to be measures of time deviation, but they are in fact the measure of difference between the cost of work planned and work done. In practice they are only indirectly and approximately related to the project's time scale.

The Earned Value model of a project is linear. This does not distort cost variances and EAC estimates, as total cost is a simple sum of costs of tasks. Regardless of the task relationships and timing, if each task cost raised by, say, 5\%, the total cost would be also $5 \%$ greater than the initial budget. Therefore, equation (8) correct.

As for schedule, the problem is more complex due to precedence relationships between tasks. As there are usually both critical and non-critical tasks in the schedule, a delay of a single task does not necessarily mean that the project finish date is going to be affected. The earned value model does not allow for this fact and each task deviation is reflected in the project's $S V$ and SPI. Similarly, if some tasks were behind schedule, and some ahead, the overall $S V$ might equal 0 and indicate that the project was on schedule, even if the schedule network logic was seriously affected.

Another drawback of the simplified timing matters is related to the following fact: completed tasks cease to affect the project's schedule variance - their $S V=0(S P I=1)$ and $B C W P$ becomes equal to $B C W S$, no matter if the tasks have been delayed or shifted to earlier of later dates. So, there are two interpretations of a task's $S V=0(S P I=1)$ : the task is according to plan or it is fully completed. This quality is shared by single tasks and the whole project (see Fig. 1: at the end of the project, $B C W P=B C W S=B A C$ ). Therefore, at a certain stage of project development (usually the last third of its duration) $S V$ and SPI cannot be considered a reliable measure of schedule deviation - either in terms of time or in terms of completed scope of works [7].

And yet another shortcoming of the Earned Value's simplified model: in general, the graphic representation of a real-life project's cumulated cost against time is a complex irregular curve, but the Earned Value model is linear. Thus, the assumption that the time variance stays in proportion to $S V$ is wrong [8]. This is illustrated by Figure 3 . 


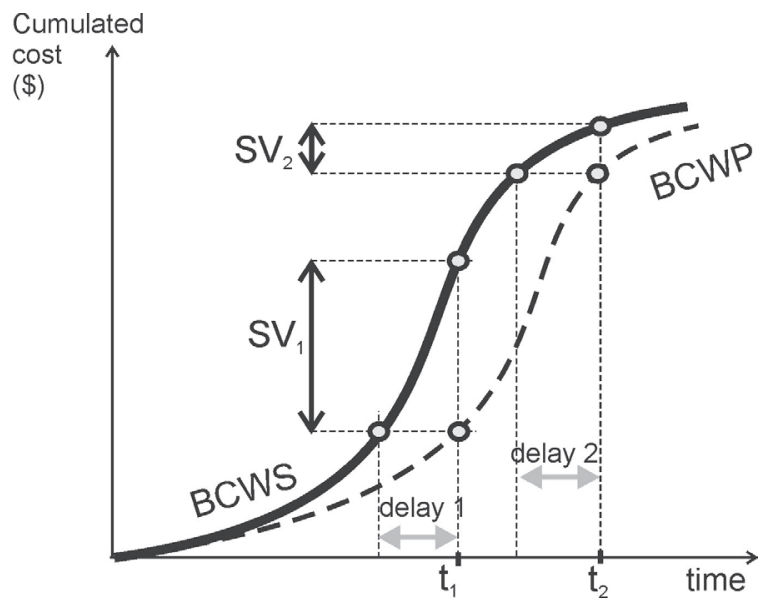

Fig. 3. Non-linear time-cost relationship - no correlation between size of delay and schedule variance.

An interesting illustration of this fact has been presented by Evensmo and Karlsen [5]. The problem they presented would be though more approachable if reversed: let's assume that a project's development has been already recorded (so the actual duration $T$ ' and final costs $E A C$ are known). Let's conduct an ex-post analysis of accuracy of SPI-based, linear "prediction" of actual duration, by analogy to EAC estimates (equation 8):

$$
T^{\prime}=\frac{T}{S P I} \text {. }
$$

\subsection{Example - issues of CPI and SPI-based estimates of project's actual cost and duration}

Let us compare two variants of a project development:

a) BCWS, BCWP and ACWP stay in close relation and are described by a polynomial of $3^{\text {rd }}$ degree representing a symmetrical S-curve [5]:

$$
\begin{aligned}
& B C W S=\frac{B A C}{T^{2}}\left(3 t^{2}-\frac{2}{T} t^{3}\right), \\
& B C W P=\frac{B A C}{T^{\prime^{2}}}\left(3 t^{2}-\frac{2}{T^{\prime}} t^{3}\right), \\
& A C W P=\frac{E A C}{T^{\prime^{2}}}\left(3 t^{2}-\frac{2}{T^{\prime}} t^{3}\right) .
\end{aligned}
$$

The parameters are: $B A C=\$ 1000$ tho., $T=10$ months (planned duration), $E A C=\$ 1200$ tho. (actual total cost), $T^{\prime}=12$ months (actual duration) (Fig. 4, Tab. 2).

b) $B C W P$ and $A C W P$ are random, but close to BCWS. BCWS is an S-curve as in a) (Fig. 5, Tab. 2). 


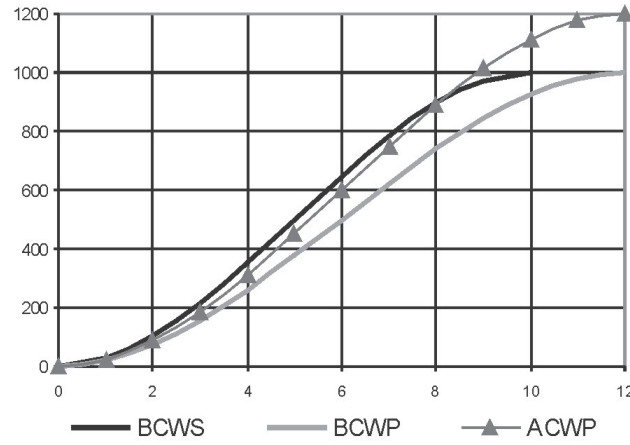

Fig. 4. Development of project a).

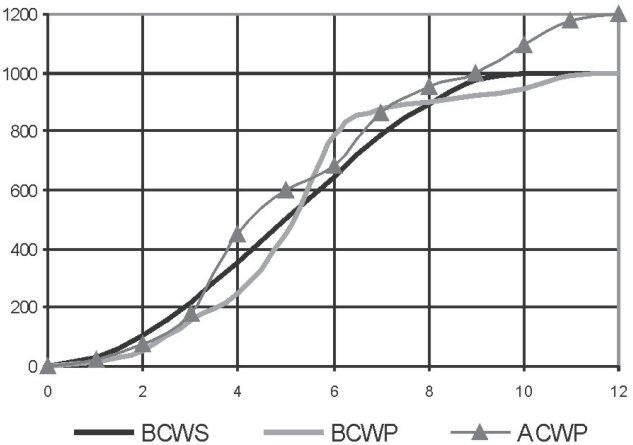

Fig. 5. Development of project b).

Table 2. Earned Value calculation - example.

\begin{tabular}{|c|c|c|c|c|c|c|c|}
\hline \multicolumn{8}{|c|}{ project a) } \\
\hline$t$ & BCWS & $B C W P$ & $A C W P$ & CPI & SPI & $E A C$ & $T^{\prime}$ \\
\hline 0 & 0 & 0,00 & 0,00 & - & - & - & - \\
\hline 1 & 28 & 19,68 & 23,61 & 0,83 & 0,70 & 1200 & 14,23 \\
\hline 2 & 104 & 74,07 & 88,89 & 0,83 & 0,71 & 1200 & 14,04 \\
\hline 3 & 216 & 156,25 & 187,50 & 0,83 & 0,72 & 1200 & 13,82 \\
\hline 4 & 352 & 259,26 & 311,11 & 0,83 & 0,74 & 1200 & 13,58 \\
\hline 5 & 500 & 376,16 & 451,39 & 0,83 & 0,75 & 1200 & 13,29 \\
\hline 6 & 648 & 500,00 & 600,00 & 0,83 & 0,77 & 1200 & 12,96 \\
\hline 7 & 784 & 623,84 & 748,61 & 0,83 & 0,80 & 1200 & 12,57 \\
\hline 8 & 896 & 740,74 & 888,89 & 0,83 & 0,83 & 1200 & 12,10 \\
\hline 9 & 972 & 843,75 & 1012,50 & 0,83 & 0,87 & 1200 & 11,52 \\
\hline 10 & 1000 & 925,93 & 1111,11 & 0,83 & 0,93 & 1200 & 10,80 \\
\hline 11 & 1000 & 980,32 & 1176,39 & 0,83 & 0,98 & 1200 & 10,20 \\
\hline 12 & 1000 & 1000,00 & 1200,00 & 0,83 & 1,00 & 1200 & 10,00 \\
\hline \multicolumn{8}{|c|}{ project b) } \\
\hline$t$ & $B C W S$ & $B C W P$ & $A C W P$ & CPI & SPI & $E A C$ & $T$, \\
\hline 0 & 0 & 0 & 0 & - & - & - & - \\
\hline 1 & 28 & 18 & 20 & 0,90 & 0,64 & 1111,11 & 15,56 \\
\hline 2 & 104 & 50 & 75 & 0,67 & 0,48 & 1500,00 & 20,80 \\
\hline 3 & 216 & 155 & 180 & 0,86 & 0,72 & 1161,29 & 13,94 \\
\hline 4 & 352 & 248 & 450 & 0,55 & 0,70 & 1814,52 & 14,19 \\
\hline 5 & 500 & 450 & 598 & 0,75 & 0,90 & 1328,89 & 11,11 \\
\hline 6 & 648 & 788 & 682 & 1,16 & 1,22 & 865,48 & 8,22 \\
\hline 7 & 784 & 876 & 866 & 1,01 & 1,12 & 988,58 & 8,95 \\
\hline 8 & 896 & 899 & 950 & 0,95 & 1,00 & 1056,73 & 9,97 \\
\hline 9 & 972 & 920 & 1000 & 0,92 & 0,95 & 1086,96 & 10,57 \\
\hline 10 & 1000 & 948 & 1097 & 0,86 & 0,95 & 1157,17 & 10,55 \\
\hline 11 & 1000 & 989 & 1174 & 0,84 & 0,99 & 1187,06 & 10,11 \\
\hline 12 & 1000 & 1000 & 1200 & 0,83 & 1,00 & 1200,00 & 10,00 \\
\hline
\end{tabular}

The above project models are purely hypothetical and created only to illustrate the key issues of the method. In fact, any curve would produce similar results. Let's assume a) and b) are construction projects and models are created for the needs of a contractor: 
a) Can be interpreted as follows: after the baseline (budget) had been created, labour costs rose. At the same time, the workers opposed to working overtime, which had been assumed while creating the schedule, so the daily output was lower than planned. However, the manager seemed to reject the obvious facts that the plan was no longer valid, and while monitoring progress, he kept referring to the initial baseline.

b) Could be a situation where prices fluctuated (so cost of e.g. materials changed) and so did labour productivity (e.g. experienced workers came and went), or wrong decisions were taken to ameliorate variances, or the baseline was wrong.

Analysing CPI and EAC development (Tab. 2, Fig. 6 and 7) one may conclude that:

- in the case of project a) CPI was stable and EAC estimate was constant and correct - no surprise as the progress curves reflected the logic of the baseline,

- in the case of project b) cost change tendencies were variable (alternative savings and cost overruns), so did the consecutive extrapolations of the final cost. There was little relationship between the project's future and its past. However, towards the end of the project the estimate approached the actual cost, so the Earned Value cost estimate was not entirely wrong.

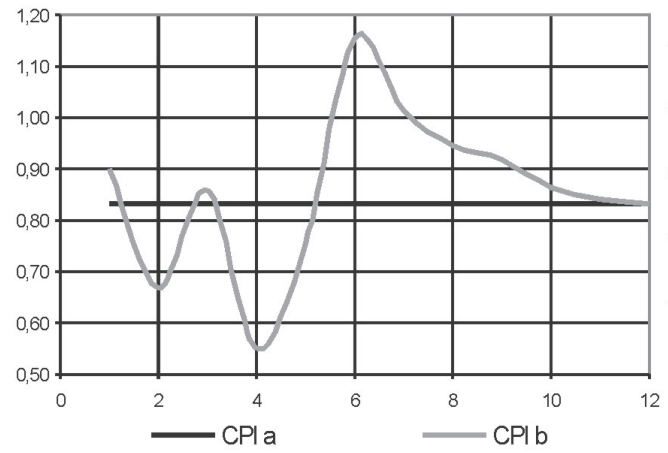

Fig. 6. CPI changes with the project progress, projects a) and b).

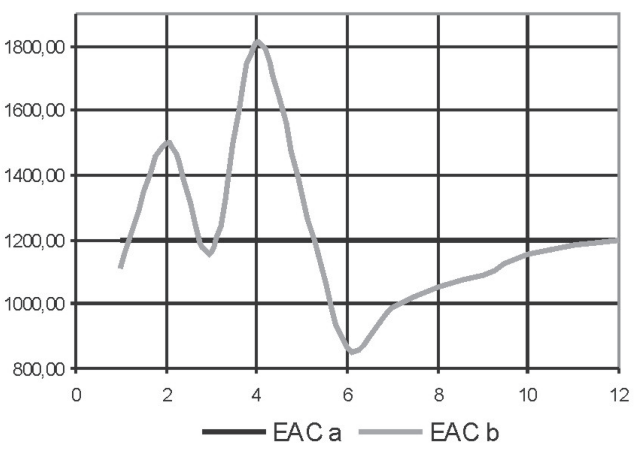

Fig. 7. Variability of assessment of final project cost - projects a) and b).

As for SPI (Fig. 8) and T' estimates (Fig. 9):

- Project a): there was a continuous growth of SPI. According to the classic Earned Value interpretation, it should indicate improving productivity. However, it is not logical as the distance between planned (BCWS) and actual progress (ACWP) graphs along the time axis grew constantly towards the later actual finish. In consequence, the linear extrapolation of total duration decreased constantly - and the final estimate was the planned duration $(T)$, not the actual duration $\left(T^{\circ}\right)$. Therefore, SPI provides misinformation in terms of project timing.

- Project b) SPI was highly variable (one could expect that as the graphic representation of the progress intersected with the plan several times). Accordingly, the linear extrapolation of total duration fluctuated, and the final estimate was also the planned duration $(T)$, not the actual duration $\left(T^{\circ}\right)$ (the same misleading result attributable to $B C W S=B C W P$ as the project finishes). 


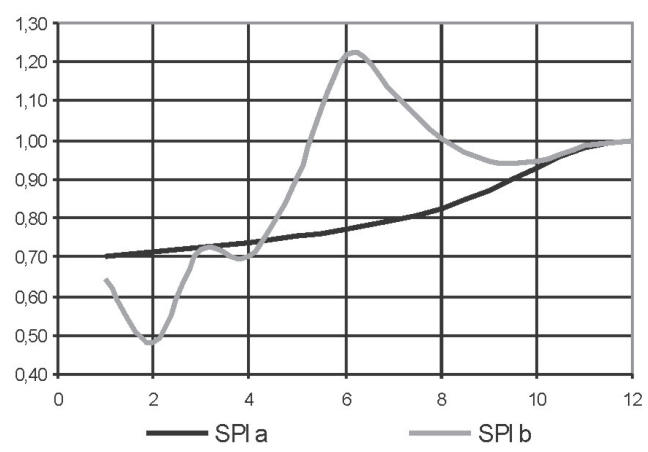

Fig. 8. SPI changes with the project progress, projects a) and b).

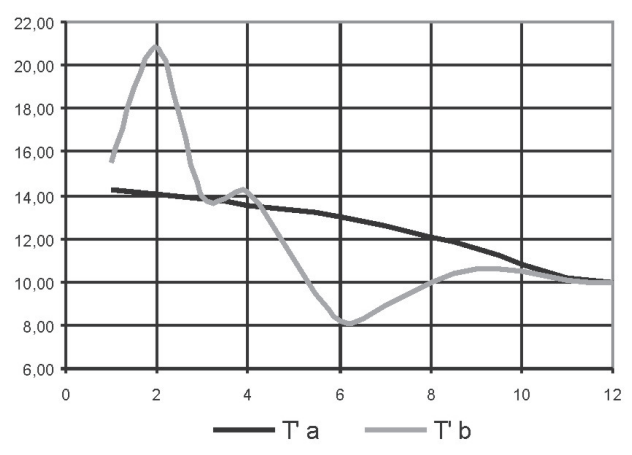

Fig. 9. Variability of assessment of project duration - projects a) and b).

The above proves that using SPI and linear extrapolation to predict total duration is wrong.

\section{Modification of the method to allow for time analysis}

\subsection{Need for simple tool to asses progress in the terms of time}

The literature on the subject argues that Earned Value method cannot (and has not been intended to) substitute more detailed analyses of project schedules and costs. However, as it proved useful in cost management, a similar simple tool for schedule analysis is being looked for. Recent development of Earned Schedule method $[9,10,11]$ is considered very promising, though it has not joined Earned Value on the list of classic management tools yet.

Earned Schedule uses the same inputs (BCWS, BCWP, T) as Earned Value, and just like in the case of the latter method, S-curves are considered to be adequate (though simplified) models of a project's time development. However, variances are to be calculated "horizontally" and expressed in time units, so instead of $S V$, there is $S V(t)$ to be calculated (Fig. 10). $S V(t)$ is to inform directly on how many time units the project is ahead or behind the plan. There had been several attempts to express schedule variance in the terms of time [7]:

1. By dividing SV by the average planned progress rate (budget divided by planned duration):

$$
S V(t)=S V \cdot \frac{T}{B A C},
$$

which measures the deviation in time units, but does not account for time deviation not being proportional to the Earned Value schedule deviation (Fig. 3). $S V(t)$ calculated this way has the same deficiencies as $S V$.

2. On the basis of actual time from the project start to the moment of analysis $(t)$ and the Earned Value's SPI; deficiencies as above:

$$
S V(t)=t \cdot(S P I-1),
$$


3. As geometric distance between BCWS i BCWP measured horizontally along the time scale; as $B C W S$ is seldom described by a mathematic function, it is not easy to calculate this distance; the following iterative formula has been proposed by Lipke $[9,10]$ :

$$
S V(t)=N+\frac{B C W P-B C W S_{N}}{B C W S_{N+1}-B C W S_{N}}-t,
$$

where $N$ is a number of units of time since the project starts up to the moment of analysis which BCWS is lower than $B C W P$ at the moment of the analysis, $B C W P$ is measured at the moment of analysis $(t), B C W S_{N}$ and $B C W S_{N+1}$ are budgeted costs of works scheduled at the $N$ th and at the $(N+1)$ th unit of time.

A website (www.earnedschedule.com/Calculator.shtml) created by the author of the third method provides spreadsheets for calculating $S V(t)$ on the basis of $B C W S$ and $B C W P$ data measured at consecutive units of time.

Having established the time variance $S V(t)$ one can calculate the "earned schedule" (ES), i.e. the period within that the works actually done should have been ready according to the plan (see Fig. 10):

$$
E S=t-S V(t) \text {. }
$$

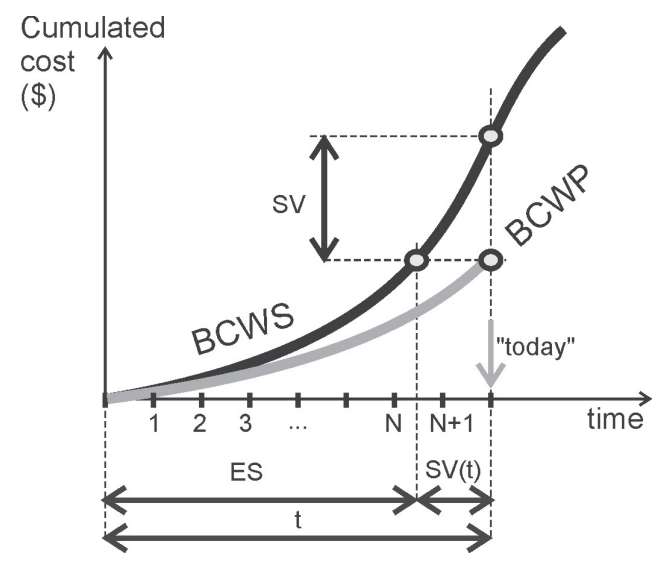

Fig. 10. Time deviation acc. to Earned Schedule method.

The method of "forecasting" the actual duration is similar to Earned Value approach to extrapolating EAC (equation 8):

$$
T^{\prime}=t+\frac{T-E S}{P F},
$$

so actual duration is the sum of time already consumed $(t)$ and the time that remained from the planned duration adjusted by a factor $(P F)$ depending on the assumed relationship between the project's current and future performance.

The relationships considered most often are [7]:

1. all tasks to follow are going to be according to schedule, $P F=1$ :

$$
T^{\prime}=T-S V(t) \text {, }
$$


2. the rate of progress is going to follow current pattern and stay in proportion to current $\operatorname{SPI}(t)$ (no time-cost relationship considered):

$$
\begin{aligned}
& S P I(t)=\frac{E S}{t}, \\
& T^{\prime}=t+\frac{T-E S}{S P I(t)}=\frac{T}{S P I(t)},
\end{aligned}
$$

3. the rate of progress is going to follow current pattern - in proportion to current schedule cost index $S C I(t)$ as a relationship between actual cost and speed of works is assumed to exist:

$$
\begin{aligned}
& S C I(t)=C P I \cdot S P I(t), \\
& T^{\prime}=t+\frac{T-E S}{S C I(t)} .
\end{aligned}
$$

\subsection{Comparison of $S P I$ and $S P I(t)$-based estimates of total duration}

An extension to the examples a) and b) of chapter 4.4. is presented in Table 3 and Table 4 accordingly. $S V(t)$ has been calculated using equation (19), and $T^{\prime}$ according to equation (24). $S V$ is measured in money units and $S V(t)$ in time units, they are not the same variances measured in different ways.

Table 3 Project a): schedule deviations and duration estimates according to Earned Value and Earned Schedule).

\begin{tabular}{cccccccccc}
\hline$t$ & $B C W S$ & $B C W P$ & $S V$ & $S P I$ & $T^{\prime} a c c . E V$ & $S V(t)$ & $E S$ & $S P I(t)$ & $T^{\prime} a c c . E S$ \\
\hline 0 & 0,00 & 0,00 & 0,00 & - & - & 0,00 & 0,00 & - & - \\
1 & 28,00 & 19,68 & $-8,32$ & 0,70 & 14,23 & $-0,30$ & 0,70 & 0,70 & 14,23 \\
2 & 104,00 & 74,07 & $-29,93$ & 0,71 & 14,04 & $-0,39$ & 1,61 & 0,80 & 12,45 \\
3 & 216,00 & 156,25 & $-59,75$ & 0,72 & 13,82 & $-0,53$ & 2,47 & 0,82 & 12,16 \\
4 & 352,00 & 259,26 & $-92,74$ & 0,74 & 13,58 & $-0,68$ & 3,32 & 0,83 & 12,06 \\
5 & 500,00 & 376,16 & $-123,84$ & 0,75 & 13,29 & $-0,84$ & 4,16 & 0,83 & 12,01 \\
6 & 648,00 & 500,00 & $-148,00$ & 0,77 & 12,96 & $-1,00$ & 5,00 & 0,83 & 12,00 \\
7 & 784,00 & 623,84 & $-160,16$ & 0,80 & 12,57 & $-1,16$ & 5,84 & 0,83 & 11,99 \\
8 & 896,00 & 740,74 & $-155,26$ & 0,83 & 12,10 & $-1,32$ & 6,68 & 0,84 & 11,97 \\
9 & 972,00 & 843,75 & $-128,25$ & 0,87 & 11,52 & $-1,47$ & 7,53 & 0,84 & 11,95 \\
10 & 1000,00 & 925,93 & $-74,07$ & 0,93 & 10,80 & $-1,61$ & 8,39 & 0,84 & 11,91 \\
11 & 1000,00 & 980,32 & $-19,68$ & 0,98 & 10,20 & $-1,70$ & 9,30 & 0,85 & 11,83 \\
12 & 1000,00 & 1000,00 & 0,00 & 1,00 & 10,00 & $-2,00$ & 10,00 & 0,83 & 12,00 \\
\hline
\end{tabular}




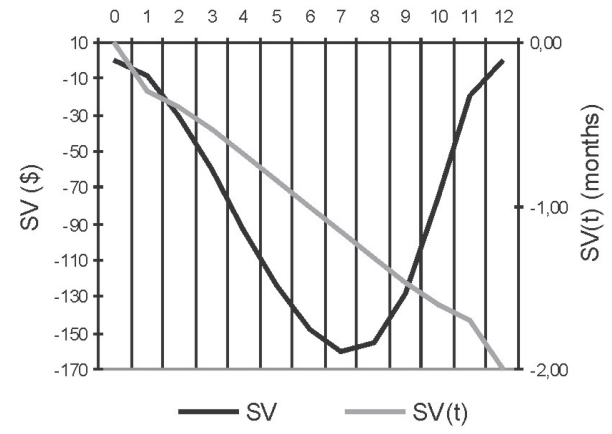

Fig. 11. $S V(\$)$ and $S V(t)$ (months) compared - project a).

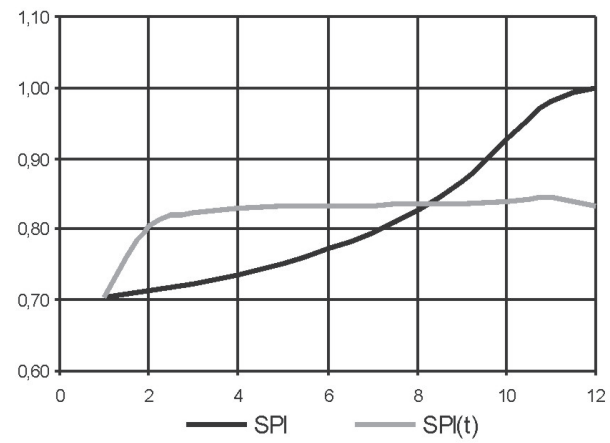

Fig. 12. SPI and SPI $(t)$ compared - project a).

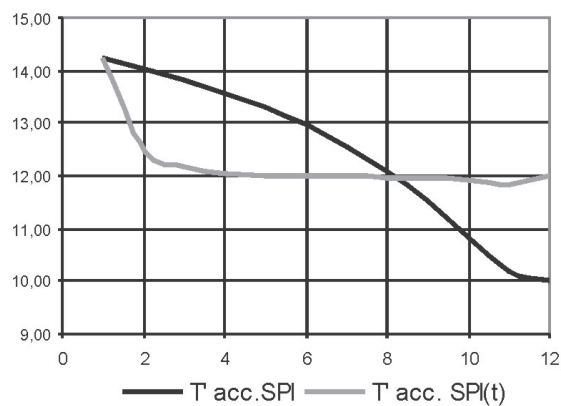

Fig. 13. Extrapolation of actual duration according to Earned Value and Earned Schedule project a).

The results of calculations speak in favour of Earned Schedule: its schedule deviation $S V(t)$ reflects the logic of project development: as graphic representations of the actual progress is steadily carried away from the plan, the time variance $S V(t)$ grows and there is no distortion towards the project finish date - quite contrary to $S V$ development (Fig. 11). The discrepancy between consecutive $T$ ' extrapolations is also much lower and closer to the actual duration (Fig. 13).

Let us repeat calculations for project b) (BCWS being a symmetrical S-curve, $B C W P$ - an irregular curve): 
Table 4. Project b): schedule deviations and duration estimates according to Earned Value and Earned Schedule).

\begin{tabular}{cccccccccc}
\hline$t$ & $B C W S$ & $B C W P$ & $S V$ & $S P I$ & $T^{\prime}$ acc. $E V$ & $S V(t)$ & $E S$ & $S P I(t)$ & $T^{\prime}$ acc. $E S$ \\
\hline 0 & 0,00 & 0,00 & 0,00 & - & - & 0,00 & 0,00 & - & - \\
1 & 28,00 & 18,00 & $-10,00$ & 0,64 & 15,56 & $-0,36$ & 0,64 & 0,64 & 15,56 \\
2 & 104,00 & 50,00 & $-54,00$ & 0,48 & 20,80 & $-0,71$ & 1,29 & 0,64 & 15,51 \\
3 & 216,00 & 155,00 & $-61,00$ & 0,72 & 13,94 & $-0,54$ & 2,46 & 0,82 & 12,22 \\
4 & 352,00 & 248,00 & $-104,00$ & 0,70 & 14,19 & $-0,76$ & 3,24 & 0,81 & 12,36 \\
5 & 500,00 & 450,00 & $-50,00$ & 0,90 & 11,11 & $-0,34$ & 4,66 & 0,93 & 10,72 \\
6 & 648,00 & 788,00 & 140,00 & 1,22 & 8,22 & 1,04 & 7,04 & 1,17 & 8,53 \\
7 & 784,00 & 876,00 & 92,00 & 1,12 & 8,95 & 0,82 & 7,82 & 1,12 & 8,95 \\
8 & 896,00 & 899,00 & 3,00 & 1,00 & 9,97 & 0,04 & 8,04 & 1,00 & 9,95 \\
9 & 972,00 & 920,00 & $-52,00$ & 0,95 & 10,57 & $-0,68$ & 8,32 & 0,92 & 10,82 \\
10 & 1000,00 & 948,00 & $-52,00$ & 0,95 & 10,55 & $-1,32$ & 8,68 & 0,87 & 11,52 \\
11 & 1000,00 & 989,00 & $-11,00$ & 0,99 & 10,11 & $-1,39$ & 9,61 & 0,87 & 11,45 \\
12 & 1000,00 & 1000,00 & 0,00 & 1,00 & 10,00 & $-2,00$ & 10,00 & 0,83 & 12,00 \\
\hline
\end{tabular}

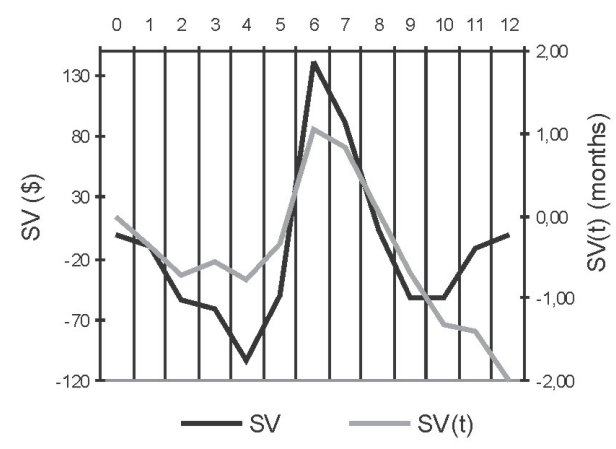

Fig. 14. $S V(\$)$ and $S V(t)$ (months) compared - project a).

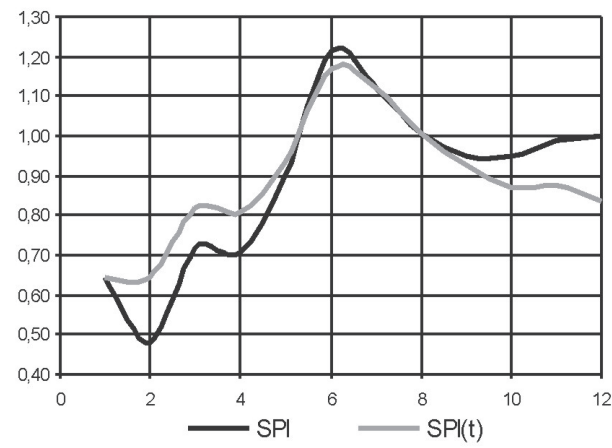

Fig. 15. SPI and SPI(t) compared - project a). 


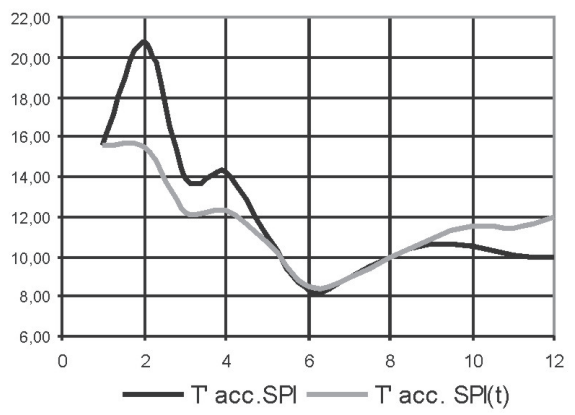

Fig. 16. Extrapolation of actual duration according to Earned Value and Earned Schedule project a).

There seems to be a correlation between $S V$ and $S V(t)$ - the trends of growth and decrease occur at the same points of time until the last third of project duration, when $S V$ curve starts to stray away and show wrongly an improving trend. Such correlation in initial phases of a project has been generally confirmed [7]. Also in this case, the Earned Schedule fluctuations of consecutive $T$ ' extrapolations are also much lower and closer to the actual duration then those extrapolated by Earned Value metrics. (Fig. 16).

\subsection{Implementing Earned Schedule}

The Earned Schedule approach, though better suited for assessing schedule status than Earned Value, rests upon the same simple model of a project: a time-cost S-curve. The method's calculations can be done on any level of a work breakdown structure (from simplest activities to project stages) in exactly the same way. For the sake of accurate progress estimates $(P C)$, it would be advisable to analyse the project on activity level (see chapter 4.1.)

However, an S-curve is a result of schedule logic. On the level of activities, projects tend to have many paths, some of them critical, other not. A tiny (if compared to total project duration) schedule variance of an activity can become a cause for substantial rearrangements in the project network, it can change critical path or order of activities, enforce a total reorganisation of works. This cannot be captured by either Earned Value or Earned Schedule calculations - potential problems might be masked by compensating positive and negative schedule deviations.

If the project was "zoomed out" so the objects of analysis were not activities, but larger complex tasks, the model might be reduced to one path and thus simplified. Within a complex task, schedule problems should be assessed by scheduling tools, and Earned Schedule method might be used to capture a more general picture of the project.

\section{Conclusions}

Earned Value, despite its being based on a much simplified model of a project, has been widely used in practice. An analysis of numerous projects the method was used at led to interesting conclusions: there occur to be statistically confirmed rules of project development [12]: 
- the final cost variance $(V A C=E A C-B A C)$ will be greater than cost variance at $20 \%$ of project development, so early negative tendencies are practically irreversible;

- after the project becomes about 20\% complete, CPI stabilises: usually, it does not change more than by $10 \%$, and in most cases its changes are for worse;

- the CPI-based EAC proves to be a reliable lower estimate of final cost overrun.

Nevertheless, the above rules have been established on the basis of US Department of Defence projects that have been assessed and managed according to specific, formalised and uniformed procedures.

Many organizations worldwide adopted Earned Value as a standard management tool (e.g. US Department of Defence [13], an Australian standard [14]). It is described in practically all management handbooks and incorporated into management software. However, if to be implemented, the method should be used according to its purpose: it is not a tool for forecasting; instead, it facilitates progress monitoring, determination of project status (on time? to budget?), identification of potentially negative occurrences and a rough estimate of their combined effect on the project's outcome. If the project is to be managed consciously, these occurrences should be then investigated into by means of more accurate methods.

\section{References}

[1] Burke R., Project Management. Planning and Control Techniques, John Wiley \& Sons, 2006.

[2] Dałkowski B.T., W trosce o publiczne pieniadze. zarzadzanie projektami metoda Earned value, Materiały III Konferencji Project Management, www.spmp.org.pl/ files/3dalkowski1.pdf.

[3] Christensen D.S., Using performance indices to evaluate the estimate at completion, Journal of Cost Analysis and Management, 1994 (Spring):17-24.

[4] Ruskin A. M., Two issues concerning the use of Earned Value Measurements, Engineering Management Journal, 2004: 16(3) s. 26-30.

[5] Evensmo J., Karlsen J.T., Earned Value Based Forecasts - Some Pitfalls, 2006 AACE International Transactions.

[6] Cass D.J., Earned Value Programs for US Dept. of Energy Projects, Cost Engineering Vol 42 No 2 2000, s. 24-43.

[7] Vandevoorde S., Vanhoucke M., A comparison of different project duration forecasting methods using earned value metrics, International Journal of Project Management, 2006: 24, s. 289-302.

[8] Corovic R., Why EVM Is Not Good for Schedule Performance Analyses (and how it could be...), The Measurable News, Winter 2006-2007, www.earnedschedule.com/papers.

[9] Lipke W., Henderson K., Earned Schedule - an emerging enhancement to EVM, www. pmicos.org/topics/EVMDEC07.pdf.

[10] Henderson K., Earned Schedule A Breakthrough, Extension to Earned Value Management, Proceedings of PMI Global Congress Asia Pacific, January 2007 www.earnedschedule. com/papers.

[11] Van De Velde R., Time Is Up: Assessing Schedule Performance with Earned Value, PM World Today - October 2007 (Vol. IX, Issue X). www.earnedschedule.com/papers. 
[12] Christensen D., Templin C., EAC evaluation methods: do they still work?, Acquisition Review Quarterly 9 (2002) s. 105-116.

[13] DOD (1997), Earned Value Management Implementation Guide, Washington: United States of America Department of Defense.

[14] AS 4817-2006, Project performance measurement using Earned Value. 